\title{
EDITORIAL NOTE: LOCAL INTELLECTUALS IN AFRICA
}

In this issue of Africa we are pleased to feature a new contribution, by Oyeniyi Okunoye, to our thematic strand on 'local intellectuals'. The intention of this strand is to highlight obscure, ephemeral or previously unpublished texts by African thinkers whose work falls outside the academic or literary mainstream. Teachers, clerks, clergy, businessmen and a host of others were engaged in the production of knowledge about African culture long before this journal was founded in 1928. They have published local histories, disquisitions on theology and philosophy, and studies of local oral genres such as riddles, proverbs and divination poetry. They have written memoirs and biographies, diaries, letters and novels. They have produced commentaries, columns, serials and huge quantities of poetry, in English and African languages, for publication in local newspapers. Others have not used the medium of writing, but have composed oral texts for live transmission or for performance on radio or television. Though ubiquitous across Africa, such local intellectual production has in the past largely been ignored by the academic world. It does not usually conform to the conventions of academic writing, it reflects local or personal interests, and it has been either unpublished or published by local presses which cannot reach an international readership. Now, however, this rich seam of intellectual work is increasingly becoming a focus of attention by historians, anthropologists and literary scholars. But the texts themselves are rarely accessible to Africanists outside the local context of their production.

In our 'local intellectuals' strand texts of this kind are introduced and analysed in a scholarly essay which provides the social and cultural context and highlights the interest of the text for a new audience. In the print version of the journal, we present, along with the scholarly essay, a short excerpt of the text in question. But in the online version, we are able to offer a much longer text, accessible as a supplement to the journal article. For example, in our inaugural contribution to the series (Africa 78(3), 2008)* Stephanie Newell retrieved a unique personal memoir by a Gold Coast clerk. The story of his adventures in Cameroon during the First World War had been serialized in the Gold Coast Leader in 1916-19, but subsequently forgotten. Newell, in her introductory essay, points out the many fascinating and puzzling features of his story, showing that texts like these are much more than 'data' to be absorbed into our own projects: they are documents that reward attention in their own right. The print version of the journal presents an excerpt of the memoir, but in the online version a link takes you to the entire 20,000-word narrative, edited and annotated by Newell.

In his contribution to the present issue, Oyeniyi Okunoye brings to Africa's readership the work of Lanrewaju Adepoju, one of Nigeria's foremost popular poets. Lanrewaju Adepoju was a pioneer in the development of a new form of public poetry, disseminated simultaneously in print, live performance and through the electronic media. As Okunoye's essay shows, this new style of poetry drew on older oral genres for inspiration, but departed from them in its transparency and its extended, coherent, socio-political and moral commentary. Adepoju composed praise poems in honour of Nigeria's politicians, but he also 
gave voice to the hardship suffered by ordinary people under economic recession and government callousness. While ubiquitous and immensely popular in southwestern Nigeria - constantly broadcast on the radio, blasted out from cassette and CD players, published and read in schools - Adepoju's poetry has not previously been translated into English. Here we have the poet's own translation, produced in the course of Okunoye's intensive work with him; we also have an extended interview in which Adepoju explains his formation as a poet and his views on the role of poetry in society. In the print version of the journal, we present Okunoye's authoritative essay on the poet and his context, and a sample poem, İlú Le ('Hard times') with its English translation. In the online journal, you will find two additional long poems with translations, as well as an interview with Adepoju.

Texts such as these constitute a rich archive of local thought and experience, experiment and commentary. They shed a fascinating light on life 'on the ground' in Africa, past and present. As the series develops, the journal will be building up a repository of on-line texts to which scholars and researchers can return over the years.

We are delighted that our new publisher, Cambridge University Press, is so supportive of this innovative use of the possibilities of online publishing. We are taking this opportunity to relaunch the 'African local intellectuals' strand, and to invite further contributions. The preferred format is an introductory essay of approximately 5,000 words and a sample text (with translation if relevant) also of approximately 5,000 words, for the print version of the journal; plus a longer local text - there is no formal word limit - appropriately edited and annotated by the contributing scholar, for the online archive.

*Africa 78.3: 384-400, 2008, doi:10.3366/E0001972008000235. Edinburgh University Press 